\title{
Pharmacokinetics of Ceftriaxione, a Third-Generation Cephalosporin, in Pediatric Patients
}

\author{
Kyoko Fukumoto, ${ }^{a}$ Shiori Aida, ${ }^{a}$ Tomohiro Oishi,${ }^{b}$ and Kazuyuki Ueno ${ }^{*}, a$ \\ ${ }^{a}$ Department Pharmaceutical Sciences, Niigata University of Pharmacy and Applied Life Sciences; 265-1 Higashijima, \\ Akiha-ku, Niigata 956-8603, Japan: and ${ }^{b}$ Niigata Prefectural Shibata Hospital; 1-2-1 Honcho, Shibata, Niigata \\ 957-8588, Japan. Received September 25, 2008; accepted April 28, 2009
}

\begin{abstract}
We monitored the serum concentration of ceftriaxone (CTRX) in order to clarify its pharmacokinetics in pediatric patients. Subjects were 21 patients undergoing CTRX therapy $(50 \mathrm{mg} / \mathrm{kg} / \mathrm{d})$ for pneumonia from January to September 2007. To determine the serum concentration of CTRX and to obtain other laboratory data, blood samples were drawn just before and after drug administration. To clarify the relationship between protein concentration and the protein binding ratio of CTRX in vitro and in vivo, the effect of human albumin on the binding ratio was investigated. Thereafter, the relationship between the protein binding ratio and the concentration of CTRX in pediatric patients was analyzed. There was no significant correlation between age and the elimination half-life of CTRX. Moreover, no significant differences were observed in the distribution volume and the clearance between pediatric patients and adults. The binding ratios increased with increased CTRX and albumin concentrations in both in vitro and in vivo studies. It was suggested that the CTRX concentration just before administration (i.e., $C_{\text {trough }}$ ) was sufficiently maintained above the mean inhibitory concentration against Streptococcus pneumoniae and Haemophilus influenzae. Therefore, CTRX administration once daily to pediatric patients with pneumonia was shown to be bacteriologically and pharmacokinetically superior in terms of efficacy.
\end{abstract}

Key words ceftriaxon; pharmacokinetics; pediatric patient; protein binding

Ceftriaxone (CTRX) is a third-generation cephalosporin possessing broad antimicrobial activity. ${ }^{1-3)}$ The pharmacokinetics and pharmacodynamics of CTRX in adults have been reported in clinical studies, and this drug shows characteristic pharmacokinetics, with a long elimination half-life $\left(t_{1 / 2}\right)$ resulting from its limited renal tubular secretion and high degree of plasma protein binding. ${ }^{2-4)}$

Multidosing per day is needed to maintain the concentration of cephalosporin antibiotics above the mean inhibitory concentration (MIC). The administration of CTRX once daily to both adults and pediatric patients with pneumonia was previously shown to be clinically and bacteriologically superior in terms of efficacy. ${ }^{5-7)}$ However, few reports on the pharmacokinetics of CTRX in pediatric patients have been published to date. The aim of this study was to evaluate the pharmacokinetics of CTRX in pediatric patients.

\section{MATERIALS AND METHODS}

Materials CTRX and cefdinir (internal standard, IS) were provided by Chugai Pharmaceutical Co., Ltd. (Tokyo, Japan) and Astelas Pharmaceutical Co., Ltd. (Hyogo, Japan), respectively. Human albumin was purchased from Wako Pure Chemical Industries (Osaka, Japan). All other chemicals were of analytical grade and commercially available.

Subjects Clinical laboratory and pharmacokinetic data were collected from 23 pediatric patients. The subjects were 23 patients undergoing CTRX therapy $(50 \mathrm{mg} / \mathrm{kg} / \mathrm{d}$, once daily) for pneumonia from January to September 2007. CTRX was dissolved in $100 \mathrm{ml}$ of normal saline and was administered intravenously at a constant rate about 60 -min period. All subjects received the CTRX therapy for $3 \mathrm{~d}$. Written informed consent was obtained from all subjects before enrollment. No subjects developed adverse effects in terms of renal function (i.e., serum creatinine level $>1.2 \mathrm{mg} / \mathrm{dl}$ ) and hepatic function (i.e., alanine transaminase or aspartate aminotranferase level $>50 \mathrm{IU} / \mathrm{l})$ during this study. No drugs were coadministered except CTRX.

Blood Sampling To determine the serum concentration of CTRX and to obtain other laboratory data, blood samples were obtained $1 \mathrm{~h}$ after the 1st drug infusion and just before the 2 nd infusion. To determine the correlation between total concentration and binding of CTRX, both total and free fraction concentrations were measured in 8 pediatric patients. To clarify the relationship between protein concentration and the protein binding ratio of CTRX in vitro and in vivo, the effect of human albumin on the binding ratio in phosphate buffer (pH 7.4) was investigated.

Preparation of Sample Solutions To determine the relationship between the protein concentration and the protein binding ratio of CTRX in vitro, the effect of human albumin on the binding ratio was investigated using $0.1 \mathrm{~m}$ phosphate buffer solution ( $\mathrm{pH}$ 7.4). After the samples were incubated for $60 \mathrm{~min}$ at $37^{\circ} \mathrm{C}$, the free fraction of the samples was obtained by ultrafiltration (a molecular weight cut-off of 10000 daltons).

Assay Serum CTRX concentrations were determined by HPLC with cefdinir as IS. Briefly, $0.2 \mathrm{ml}$ of serum, $100 \mu \mathrm{l}$ of the IS solution $(1 \mathrm{mg} / \mathrm{ml})$ and $2 \mathrm{ml}$ of methanol were mixed and centrifuged. The upper layer was evaporated, and the residue was reconstituted in water before injection into the HPLC system. The HPLC system consisted of a reversephase column (Shim-pack, CLC-ODS, Shimadzu Corp., Kyoto, Japan) and an ultraviolet absorbance detector set at $270 \mathrm{~nm}$. The mobile phase consisted of a mixture (pH 3.0) of phosphate buffer, methanol and triethylamine $(76: 24: 8$ by volume), and the flow rate was $0.5 \mathrm{ml} / \mathrm{min}$. The retention times of the IS and CTRX were 15 and $19.6 \mathrm{~min}$, respectively. The minimum measurable concentration in this system was $1 \mu \mathrm{g} / \mathrm{ml}$ in $0.2 \mathrm{ml}$ of serum. Inter- and intra-day varia- 
Table 1. Pharmacokinetics of CTRX in 21 Pediatric Patients

\begin{tabular}{lcccccc}
\hline \hline & $\begin{array}{c}\text { Age } \\
(\text { year })\end{array}$ & $\begin{array}{c}C_{\text {peak }} \\
(\mu \mathrm{g} / \mathrm{ml})\end{array}$ & $\begin{array}{c}C_{\text {trough }} \\
(\mu \mathrm{g} / \mathrm{ml})\end{array}$ & $\begin{array}{c}t_{1 / 2} \\
(\mathrm{~h})\end{array}$ & $\begin{array}{c}V_{\mathrm{d}} \\
(1 / \mathrm{kg})\end{array}$ & $\begin{array}{c}C L \\
(1 / \mathrm{h} / \mathrm{kg})\end{array}$ \\
\hline Mean & 3.21 & 546 & 25.0 & 4.87 & 0.128 & 0.0179 \\
S.D. & 2.16 & 437 & 21.0 & 1.06 & 0.055 & 0.0061 \\
CV (\%) & & 80.0 & 84.0 & 21.8 & 43.0 & 34.1 \\
Min & 0.54 & 229 & 9 & 2.88 & 0.05 & 0.006 \\
Max & 8.49 & 1934 & 57 & 6.76 & 0.218 & 0.0274 \\
\hline
\end{tabular}

$C_{\text {eak }}$ is the concentration after administration, $C_{\text {trou }}$ is the concentration just before administration, $t_{1 / 2}$ is the elimination half-life; $V_{\mathrm{d}}$ is the distribution volume, $C L$ is the total clearance of CTRX, Min is the minimum value, Max is the maximum value.

tions were $<5.0 \%$. The free fraction of the serum and spiked samples were obtained by ultrafiltration using a disposable ultrafilter (Kurabo Industries, Ltd., Osaka, Japan).

Pharmacokinetic Analysis To evaluate the pharmacokinetics of CTRX, pharmacokinetic parameters were obtained using the following equations:

$$
t_{1 / 2}=\ln 2 / K_{\mathrm{e}}=[(\ln 2) \times T] / \ln \left(C_{\text {peak }}-C_{\text {trough }}\right), V_{\mathrm{d}}=\text { Dose } / C_{\text {peak }}, C L=K_{\mathrm{e}} \times V_{\mathrm{d}}
$$

$C_{\text {peak }}$ is the CTRX concentration after administration, $C_{\text {trouph }}$ is the CTRX concentration just before administration, $T$ is the interval from $C_{\text {peak }}$ to $C_{\text {trough }}, V_{\mathrm{d}}$ is the distribution volume, and $C L$ is the total clearance of CTRX.

Statistical Analysis Data are expressed as mean \pm standard deviation (S.D.). Statistical analysis was performed using the Student's $t$-test, and significance was set at $p<0.05$.

\section{RESULTS}

The pharmacokinetic parameters obtained are shown in Table 1. As for the relationship between age and $t_{1 / 2}$ and age and the $C L$ of CTRX, no significant correlation was observed, as shown in Fig. 1. The relations between serum total concentrations and binding ratio of CTRX in pediatric patients is shown in Fig. 2, that between albumin concentrations and binding ratio in phosphate buffer $(\mathrm{pH} 7.4)$ is shown in Fig. 3, and that between total CTRX concentrations and binding ratio in both human plasma and phosphate buffer solution ( $\mathrm{pH} \mathrm{7.4)} \mathrm{containing} 4.0 \mathrm{~g} / \mathrm{dl}$ is shown in Fig. 4. It was observed that protein binding ratio increased with CTRX and albumin concentrations.

\section{DISCUSSION}

The administration of CTRX once daily to adults with pneumonia has been shown to be clinically, bacteriologically and pharmacologically superior in terms of efficacy. ${ }^{1-3)} \mathrm{Al}-$ though several reports showing the clinical efficacy of CTRX in pediatric patients have been published, ${ }^{6,7)}$ the pharmacokinetics of this drug in pediatric patients when administered once daily has not yet been reported.

The $C L$ of CTRX in the pediatric subjects was $0.0179 \pm$ $0.0061 \mathrm{l} / \mathrm{h} / \mathrm{kg}$. It was reported that the mean $C L$ in normal adults (dosage regimen was $2 \mathrm{~g} \mathrm{q} 12 \mathrm{~h}$ ) was $0.0017 \mathrm{l} / \mathrm{h} / \mathrm{kg}^{8}$; therefore, no significant difference was observed in the $C L$ between pediatric patients and adults. Hayton and Stoeckel ${ }^{5)}$ reported that changes in the $C L$ of CTRX were age-associated and its dosage should be reduced in subjects less than 1 week of age. The mean \pm S.D. of $C L$ in subjects aged $1-8 \mathrm{~d}$,

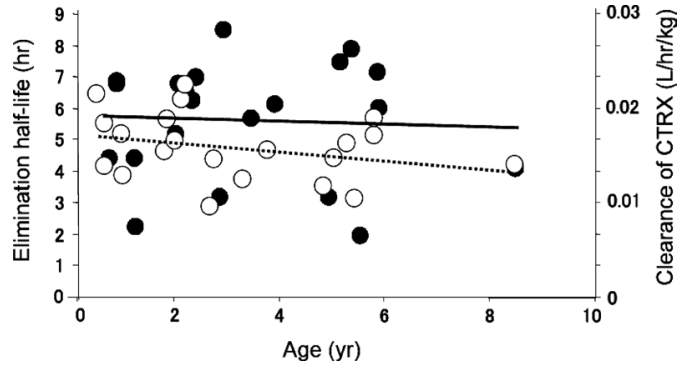

Fig. 1. Relations between Age and Elimination Half-Life $(O)$ and Age and Clearance of CTRX (•)

The regression equations were determined by the least-squares method, where $y=-0.143 x+5.22, R^{2}=0.085(\bigcirc)$ and $y=-0.0001 x+0.0183, R^{2}=0.0023$.

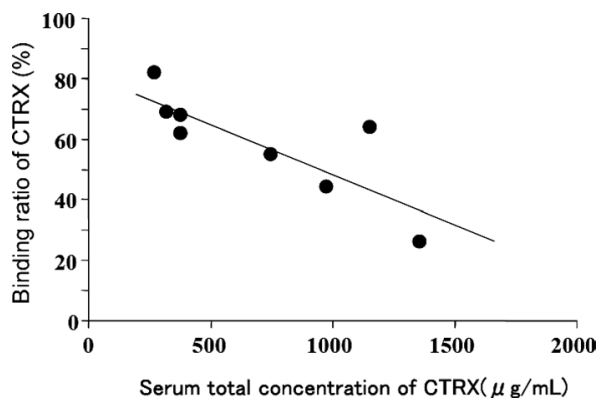

Fig. 2. Relation between Total Concentration and Binding Ratio of CTRX in Pediatric Patients

The regression equations were determined by the least-squares method, where $y=-0.033 x+81.8, R^{2}=0.658$.

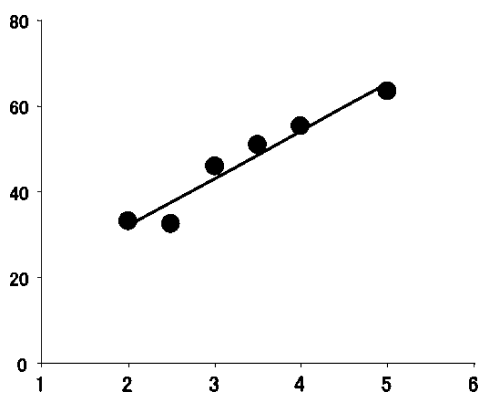

Fig. 3. Relation between Albumin Concentration and Binding Ratio of CTRX in Phosphate Buffer (pH 7.4)

The regression equations were determined by the least-squares method, where $y=-11.1 x+9.89, R^{2}=0.940, p<0.01$.

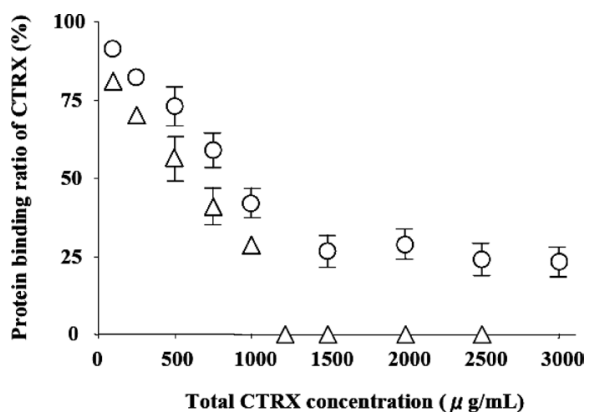

Fig. 4. Relation between Total CTRX Concentration and Binding Ratio in Both Human Plasma $(\bigcirc)$ and Phosphate Buffer Solution (pH 7.4) Containing $4.0 \mathrm{~g} / \mathrm{dl}(\triangle)$ 
$9-30 \mathrm{~d}, 1-12$ months and $1-6$ years were $0.0206 \pm 0.0076$, $0.0156 \pm 0.0109,0.0154 \pm 0.067$ and $0.0154 \pm 0.00261 / \mathrm{h} / \mathrm{kg}$, respectively. In their study, it appeared that the $C L$ of CTRX in neonates was slightly higher than that seen in the present study. However, our subjects did not include neonates and thus the $C L$ of CTRX in this study was almost the same as that in Hayton and Stoeckel's study. As shown in Fig. 1, no significant correlation was observed between age and $t_{1 / 2}$. In a previous study, ${ }^{6}$ the means \pm S.D. of $t_{1 / 2}$ when $10 \mathrm{mg} / \mathrm{kg}$ and $20 \mathrm{mg} / \mathrm{kg}$ of CTRX were administered to pediatric patients (5-13 years of age) were $6.6 \pm 2.7$ and $5.1 \pm 1.1 \mathrm{~h}$, respectively. On the other hand, the mean \pm S.D. of $t_{1 / 2}$ of the subjects $(0.54-8.49$ years of age) in the present study was $4.87 \pm 1.06 \mathrm{~h}$. Therefore, no significant difference was observed in the $t_{1 / 2}$ among the dosages, suggesting that age does not affect $C L$ in either adults or pediatric patients.

As shown in Figs. 2-4, a significant correlation was observed between albumin concentrations and binding ratios, and significant associations between total concentration and CTRX binding ratio in pediatric patients, phosphate buffer solution containing human albumin, and human serum were identified. The CTRX binding ratio increased with increased albumin concentration. In contrast, the CTRX binding ratio decreased in proportion to the total CTRX concentration. These results suggest that the CTRX binding ratio is dependent on the total CTRX concentration. It has been reported that the CTRX binding ratio to albumin is high; however, when the total CTRX concentration in the present study was above $1500 \mu \mathrm{g} / \mathrm{ml}$, the binding ratio decreased to almost zero in phosphate buffer. On the other hand, a difference in the binding ratio between the phosphate buffer solution and human serum was observed, and when the total CTRX concentration was more than $1500 \mu \mathrm{g} / \mathrm{ml}$, the binding ratio was fixed to about $25 \%$ in human samples. It has also been reported that fatty acid is related to the CTRX binding ratio. ${ }^{4)}$ This suggests that the difference in the binding ratio between the phosphate buffer solution and the human serum samples might be due to fatty acid. Therefore, the excretion rate of this drug and its transmigration ratio to tissue may be increased when the total CTRX concentration is high. Careful monitoring is thus necessary when the total CTRX concentration is high. Further studies are needed to determine the mechanism underlying the relationship between the CTRX binding ratio and the concentration of fatty acid.

The mean \pm S.D. of $C_{\text {trough }}$ in the subjects receiving $50 \mathrm{mg} / \mathrm{kg}$ of CTRX was $25.0 \pm 21.0 \mu \mathrm{g} / \mathrm{ml}$. The $\mathrm{MIC}_{90}$ values of CTRX against Escherichia coli and Klebsiella pneumonia were 0.25 and $0.125 \mu \mathrm{g} / \mathrm{ml}$, respectively. ${ }^{9,10)}$. The subjects in this study were administered CTRX for pneumonia, the $\mathrm{MIC}_{90}$ values of CTRX against Streptococcus pneumoniaes and Haemophiolus influenzae were $0.25-1.0$ and $0.25 \mu \mathrm{g}$ / $\mathrm{ml}$, respectively. ${ }^{11,12)}$ Therefore, when CTRX was administered once daily, it was observed that $C_{\text {trough }}$ was sufficiently maintained above the MIC. On the other hand, the CTRX binding ratio decreased in proportion to the total CTRX concentration. The binding ratio in the total CTRX concentration below $250 \mu \mathrm{g} / \mathrm{ml}$ was about $80-90 \%$ for the in vitro data (serum), and that below $250 \mu \mathrm{g} / \mathrm{ml}$ obtained from the regression equation between the binding ratio and total concentration in pediatric patients was about $80 \%$. This binding ratio further decreased when the total CTRX concentration was higher than $250 \mu \mathrm{g} / \mathrm{ml}$. Thus, when CTRX was administered once daily, it was suggested that $C_{\text {trough }}$ was sufficiently maintained above the MIC. Therefore, the administration of CTRX once daily to pediatric patients with pneumonia was shown to be bacteriologically superior in terms of efficacy.

Taken together, the results indicate that there is no difference in the pharmacokinetic parameters between adults and pediatric patients except in neonates. Therefore, the administration of CTRX once daily to pediatric patients (except neonates) with pneumonia shows superior efficacy.

\section{REFERENCES}

1) Angehon P., Probst P. J., Reiner R., Then R. L., Antimicrob. Agents Chemother, 18, 913-921 (1980).

2) Stoeckel K., McNmara P. J., Brandt P., Plozza-Nottebrock H., Ziegler W. H., Clin. Pharmacol. Ther, 29, 650-657 (1981).

3) Patel I. M., Chen S., Parsonnet M., Hackman M. R., Brooks M. A., Konikoff J., Kaplan S. A., Antimicrob. Agents Chemother., 20, 634 641 (1981).

4) McNamara P. J., Trueb V., Stoekel K., Biochem. Pharmacol., 40, $1247-1253$ (1990).

5) Hayton W. L., Stoeckel K., Clin. Pharmacokinet., 11, 76-86 (1986).

6) Fujita K., Sakata H., Murono K., Yoshioka H., Jpn. J. Antibiot., 37, 2271-2282 (1984).

7) Satoh Y., Iwata S., Akita H., Murai T., Hayano S., Okikawa T., Osano M., Jpn. J. Antibiot., 37, 2034-2048 (1984).

8) Pollock A. A., Tee P. E., Patel I. H., Spicehanler J., Simberkoff M. S., Rahal J. J., Antimicrob. Agents Chemother, 22, 816-823 (1982).

9) Nishino T., Ohtsuki M., Senda N., Tanino T., Jpn. J. Chemother., 32, $62-76$ (1984)

10) Ubukata K., Nonoguchi R., Yamashita N., Gotoh A., Konno M., Jpn. J. Chemother, 56, 32-38 (1984)

11) Fujimura T., Yoshida I., Itoh Y., Tachibana M., Kaku M., Kanemitsu K., Jpn. J. Chemother, 56, 543-561 (2008).

12) Yoshida I., Fujimura T., Itoh Y., Tachibana M., Kaku M., Kanemitsu K., Jpn. J. Chemother., 56, 562-579 (2008). 